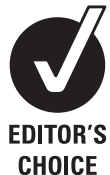

See Editorial, p 1

- An additional table is published online only. To view this file please visit the journal online (http://thorax.bmj.com)

${ }^{1}$ National Heart Lung Institute, Imperial College, London, UK ${ }^{2}$ Institute of Health Sciences Education, Queen Mary University of London, London, UK

\section{Correspondence to}

P G J Burney, National Heart Lung Institute, Emmanuel Kaye Building, Imperial College, London SW3 6LR, UK; p.burney@imperial.ac.uk

Received 15 July 2010 Revised 3 September 2010 Accepted 9 September 2010 Published Online First 26 October 2010

\title{
Forced vital capacity, airway obstruction and survival in a general population sample from the USA
}

\author{
P G J Burney, ${ }^{1}$ R Hooper ${ }^{1,2}$
}

ABSTRACT

Background Many studies show a link between forced expiratory volume in $1 \mathrm{~s}\left(\mathrm{FEV}_{1}\right)$ and survival in the general population and this has been interpreted as a link between airway obstruction and survival. However, the observation that vital capacity is also associated with survival weakens this interpretation.

Methods Data on spirometry and survival were taken from the Atherosclerosis Risk in Communities (ARIC) limited access dataset. Survival among 7489 participants with usable spirometry and complete data was regressed against measures of ventilatory function after controlling for many other factors likely to be associated with survival.

Results Survival was strongly associated with forced vital capacity (FVC) after adjustment for $\mathrm{FEV}_{1}$, but not the other way round. The fully adjusted hazard ratio (HR) associated with high FVC was 0.90 in men $195 \% \mathrm{Cl} 0.80$ to $1.00 ; p=0.049)$ and 0.82 in women $(95 \% \mathrm{Cl} 0.70$ to $0.95 ; \mathrm{p}=0.01)$. This compares with 0.98 for $\mathrm{FEV}_{1}$ in men (95\% $\mathrm{Cl} 0.90$ to 1.07 ; p.0.72) and 1.01 in women $(95 \%$ $\mathrm{Cl} 0.89$ to $1.15 ; p=0.84)$. There was no association between survival and airway obstruction as measured by the $\mathrm{FEV}_{1} / \mathrm{FVC}$ ratio.

Conclusions FVC but not airway obstruction predicts survival in asymptomatic adults without chronic respiratory diagnoses or persistent respiratory symptoms. The association is not explained by age, anthropometry, smoking, income occupation or blood pressure. As FVC later in life, cardiovascular risk, type II diabetes mellitus and low-grade systemic inflammation are all associated with poor fetal growth, these other conditions may be partly responsible for the poor survival in those with low FVC

\section{INTRODUCTION}

Over the last 40 years many studies have demonstrated a relation between survival and forced expiratory volume in $1 \mathrm{~s}\left(\mathrm{FEV}_{1}\right)$ in general population samples, ${ }^{12}$ and have shown that low $\mathrm{FEV}_{1}$ is associated with high mortality from cardiovascular causes. ${ }^{3}{ }^{4}$ This has been interpreted as evidence for an association between chronic obstructive lung disease (COPD) and atherosclerosis. ${ }^{5} \mathrm{FEV}_{1}$, however, does not define COPD and an association has also been identified between mortality and vital capacity. ${ }^{3}$ Very few studies have specifically investigated which component of ventilatory function best predicts survival, and the few studies that have looked at the prognosis associated with a lower ratio of $\mathrm{FEV}_{1}$ to forced vital capacity (FVC) have given inconclusive answers. Anderson showed an association between the $\mathrm{FEV}_{1} / \mathrm{FVC}$ ratio and survival in New Guinea, ${ }^{6}$ but neither Friedman ${ }^{3}$ in his original study nor Lange in the Copenhagen
Heart Study ${ }^{4}$ showed a convincing association with cardiovascular end points.

In this analysis we have used data from the Atherosclerosis Risk in Communities (ARIC) limited access dataset to separate out the effects of different spirometric indices on survival.

\section{METHODS}

Participants in the ARIC study were drawn from the general population of four American communities: Forsyth County, North Carolina; Jackson, Mississippi; the north-western suburbs of Minneapolis, Minnesota; and Washington County, Maryland. In Jackson, only black subjects were included in the sample. Four thousand participants aged 45-64 years were to be selected from each centre. $^{7}$

The protocol was ambitious and mainly aimed at identifying potential risk factors for cardiovascular disease. Importantly for this analysis, $\mathrm{FEV}_{1}$ and FVC were also measured using a volume displacement water-sealed spirometer.' From a minimum of five forced expiratory manoeuvres, at least three acceptable blows were required and the best of these selected according to the contemporary ATS guidance. $^{89}$ Quality control was managed from a central monitoring service at Johns Hopkins University. ${ }^{7}$ Subjects were followed up over the following years and, in particular, any deaths were noted.

The limited access dataset includes those participants in the ARIC cohort who gave informed consent for their data to be used in this way, and in some instances has small subgroups recoded to preserve anonymity. We analysed only individuals who were asymptomatic at baseline-that is, excluding those reporting persistent cough or phlegm, wheeze, breathlessness or doctor-diagnosed asthma, chronic bronchitis or emphysema. Except where otherwise indicated, we analysed only those with usable spirometry (at least two reproducible manoeuvres out of at least three judged to be acceptable).

In those with complete data, we modelled the effects on overall mortality of baseline characteristics observed at entry to the study. These included age, height, body mass index (BMI), waist-hip ratio, sitting height, income category, current working status, most recent occupation, ever smoked, current smoking, pack-years of smoking, education level and systolic blood pressure. Participants for whom the most recent occupation was missing were not distinguished from those with 'other' occupations in the limited access dataset, and the relatively high proportion of people with unreported income were analysed as a separate 
category. We analysed those participants with complete data on the remaining predictors and outcome. We compared characteristics of asymptomatic individuals with and without complete data using a Mann-Whitney test (age) and $\chi^{2}$ tests (sex and smoking status).

Mortality was analysed using Cox regression, looking at men and women separately. We looked at main effects of age, height, BMI, waist-hip ratio, sitting height, income category, current working status, most recent occupation, ever smoked, current smoking, pack-years of smoking, education category, systolic blood pressure and ethnic group (divided into black and non-black subjects in the limited access dataset). We also looked at what happened if we included quadratic effects of the continuous variables age, height, BMI, waist-hip ratio, sitting height, pack-years and systolic blood pressure. We concluded that linear effects were reasonable for all the continuously-scaled variables except for systolic blood pressure, which we divided into quintiles (calculated separately for men and women).

Having obtained in this way a model for the effects of confounding variables on mortality, we considered the additional effects of $\log \left(\mathrm{FEV}_{1}\right), \log (\mathrm{FVC})$ and $\log \left(\mathrm{FEV}_{1} / \mathrm{FVC}\right.$ ratio). Taking logarithms of lung function measurements made conceptual sense because the three log values are linearly related, and also produced better-fitting models.

We also conducted a sensitivity analysis using all asymptomatic subjects with a recorded assessment of lung function regardless of quality.

All analyses were done with Stata 11.

\section{RESULTS}

The study began in 1986 and recruited 15792 participants, 15732 of whom gave permission for their data to be included in the ARIC limited access dataset; 11106 were asymptomatic, 7631 had usable spirometry and 7489 had complete data. There were 792 deaths recorded over 102576 person-years of follow-up (figure 1).

There were small but statistically significant differences in the characteristics of asymptomatic individuals with and without complete data. Of those with complete data, 3982 (53\%) were women compared with 2045 (57\%) of those without complete data $(p=0.001)$. The median interquartile range (IOR) age of those with complete data was 53 (49-58) compared with 54 (49-59) for those without complete data $(\mathrm{p}<0.001)$. Of those with complete data, 1478 (20\%) were current smokers and 2635 $(35 \%)$ were ex-smokers, compared with 826 (23\%) and 1080 $(30 \%)$ of those without complete data $(\mathrm{p}<0.001)$.

The characteristics of asymptomatic individuals with usable spirometry and complete data are shown in table 1. The association of these factors (excluding lung function) with mortality is given in table 2. Table 3 shows that both $\mathrm{FEV}_{1}$ and FVC were strongly associated with mortality (expressed as a hazard ratio (HR)) even after adjusting for the identified confounders, although there was no association between the $\mathrm{FEV}_{1} / \mathrm{FVC}$ ratio and survival for either sex. When further mutual adjustment was made for $\mathrm{FEV}_{1}$ and FVC, only FVC remained as an important predictor of mortality in the model, a higher FVC being associated with a lower HR: 0.90 for men (95\% CI 0.81 to $1.00 ; p=0.049)$ and 0.82 for women ( $95 \%$ CI 0.70 to $0.95 ; \mathrm{p}=0.01)$. $\mathrm{FEV}_{1}$ had no association with survival independent of its association with FVC.

Among 2988 asymptomatic black people, 1418 (47\%) had usable spirometry while, among 8118 asymptomatic non-black people, $6213(77 \%)$ had usable spirometry $(\mathrm{p}<0.001)$. However, when we repeated the analyses in table 3 using all individuals with spirometry data regardless of quality, the results were qualitatively the same.

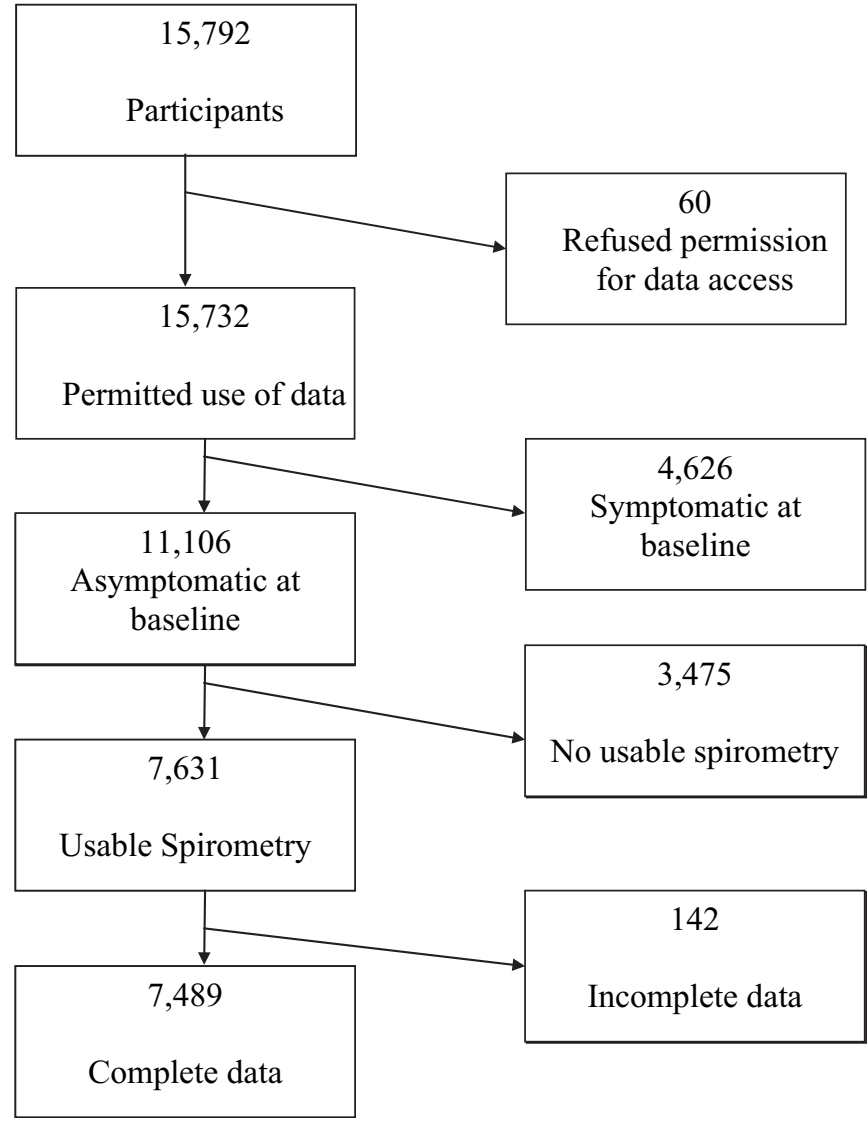

Figure 1 Inclusion and exclusion of participants from the analyses.

\section{DISCUSSION}

In this general population cohort from the USA, excluding participants with chronic respiratory diagnoses or persistent respiratory symptoms, survival was associated with FVC in both men and women. Neither the $\mathrm{FEV}_{1}$ nor the $\mathrm{FEV}_{1} / \mathrm{FVC}$ ratio had any independent effect on survival. This result is at variance with the general assumption that the association of $\mathrm{FEV}_{1}$ with mortality-and more specifically with cardiovascular mortality-represents an association with airways obstruction.

Supporting our findings, there have been several other studies showing an association between FVC and both survival ${ }^{6} 1011$ and more specific cardiovascular outcomes, ${ }^{3} 412$ and this alone makes interpretation of $\mathrm{FEV}_{1}$ as a marker of obstruction less convincing. Although it is true that some studies have failed to find an association with $\mathrm{FEV}_{1}{ }^{13}$ this has been uncommon. In addition, where it has been studied, there is very little evidence of the $\mathrm{FEV}_{1} / \mathrm{FVC}$ ratio being of prognostic significance. ${ }^{3} 4$

It is extremely unlikely that the restriction observed in this analysis is due to the restrictive lung diseases as they are usually defined. These are rare conditions. Some restriction may be seen where there is a physical constriction of the lungs due either to abdominal obesity or where rib or diaphragm movement is limited. ${ }^{14}$ We were unable to specifically exclude the latter, but the findings here are adjusted for BMI and waist-hip ratio. Some restriction may also be seen in early obstructive airway disease due to gas trapping. ${ }^{15} 16$ We have no measurement of residual volume in this study, but it seems extremely unlikely that a subtle measure of early obstruction would have a strong association with mortality but that the $\mathrm{FEV}_{1} / \mathrm{FVC}$ ratio would not.

The association between mortality and low ventilatory function has been ascribed to comorbidities-specifically 
Table 1 Baseline characteristics of asymptomatic individuals with usable spirometry and complete data

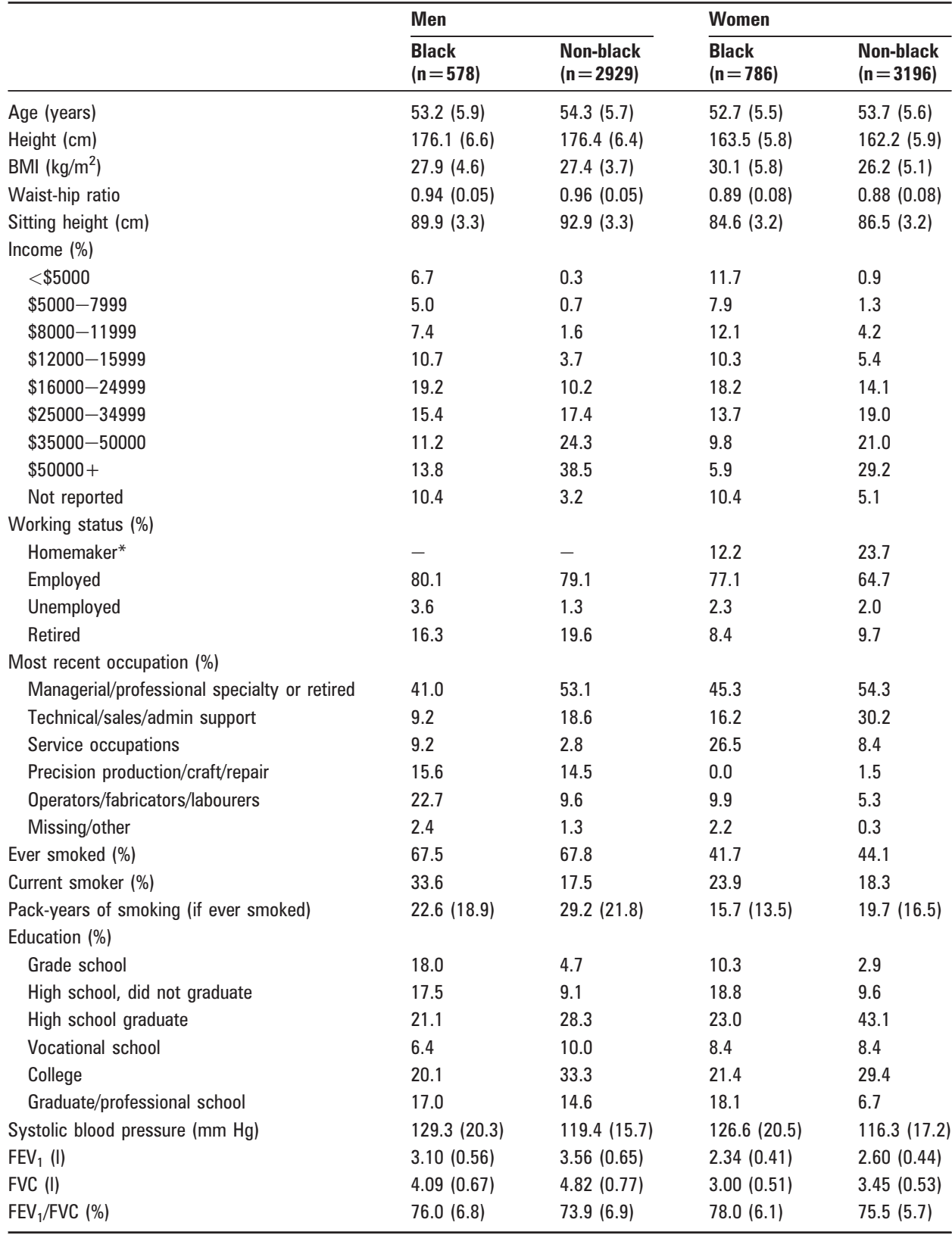

Values are mean (SD) or percentage.

* In the dataset, male subjects who reported they were homemakers were given a missing value for current working status to help preserve anonymity. Since these participants could not be identified they were not included in the analysis. $\mathrm{BMI}$, body mass index; $\mathrm{FEV}_{1}$, forced expiratory volume in $1 \mathrm{~s}$; FVC, forced vital capacity.

cardiovascular disease- and the link with cardiovascular disease is often ascribed to common risk factors such as smoking. The assumption behind many of these speculations, however, has been that the relevant pathology was airway obstruction. ${ }^{5}$ The same factors may, however, affect FVC. In the ARIC study, FVC was more closely associated with traffic exposure than was the $\mathrm{FEV}_{1} / \mathrm{FVC}$ ratio, ${ }^{17}$ and incident coronary heart disease was linked to both FVC and $\mathrm{FEV}_{1}{ }^{18}$ Interestingly, the link with FVC was particularly noted in non-smokers and after adjusting for many other cardiovascular risk factors.

A link between diabetes (another comorbidity that could explain an excess mortality) and low FVC has been reported from many studies including ARIC, ${ }^{19}$ and has more often been ascribed to an adverse effect of diabetic pathology on ventilatory function, ${ }^{20}$ a view that is supported by the more rapid decline of lung function in those with diabetes. ${ }^{21}$
A further possibility is that the low FVC associated with increased mortality is associated with poor intrauterine lung growth. Barker's early study of adult ventilatory function and birth weight reported an association between lower birth weights and lower $\mathrm{FEV}_{1}$ in adulthood but did not report an association with a reduction in FVC. ${ }^{22}$ Since then, however, in spite of a few studies reporting no association between birth weight and subsequent ventilatory function, ${ }^{23-25}$ most studies have shown that the deficit in adult lung function associated with low birth weight is a deficit in FVC as well as $\mathrm{FEV}_{1}{ }^{26} 27$ and not in the $\mathrm{FEV}_{1} / \mathrm{FVC}$ ratio. ${ }^{28-33}$

As cardiovascular disease is also closely associated with birth weight, ${ }^{34}$ this may also explain the association between lung function and cardiovascular mortality. The metabolic syndrome has similarly been associated with low birth weight, ${ }^{35}$ and this could also explain the particularly strong association of low lung 
Table 2 Association of potential confounders with mortality

\begin{tabular}{|c|c|c|c|c|c|c|}
\hline & \multicolumn{3}{|l|}{ Men } & \multicolumn{3}{|c|}{ Women } \\
\hline & HR & $95 \% \mathrm{CI}$ & p Value & HR & $95 \% \mathrm{Cl}$ & p Value \\
\hline Age (per year) & 1.09 & 1.06 to 1.11 & $<0.001$ & 1.08 & 1.05 to 1.10 & $<0.001$ \\
\hline BMI (per $\left.\mathrm{kg} / \mathrm{m}^{2}\right)$ & 1.03 & 1.00 to 1.06 & 0.035 & 1.02 & 1.00 to 1.05 & 0.10 \\
\hline Waist-hip ratio (per unit) & 32.7 & 3.4 to 311.4 & 0.002 & 3.7 & 0.6 to 21.4 & 0.15 \\
\hline Unreported income & 0.71 & 0.43 to 1.15 & 0.16 & 0.75 & 0.45 to 1.23 & 0.25 \\
\hline Working status & & & 0.023 & & & 0.29 \\
\hline Homemaker† & - & - & & 1.33 & 0.88 to 2.01 & \\
\hline Employed & 1.00 & - & & 1.00 & - & \\
\hline Unemployed & 1.60 & 0.91 to 2.79 & & 0.95 & 0.44 to 2.05 & \\
\hline Retired & 1.46 & 1.07 to 1.98 & & 0.97 & 0.60 to 1.55 & \\
\hline Precision production/craft/repair & 0.93 & 0.65 to 1.33 & & 0.47 & 0.11 to 2.01 & \\
\hline Operators/fabricators/labourers & 1.14 & 0.79 to 1.65 & & 1.12 & 0.63 to 2.01 & \\
\hline Missing/other & 0.61 & 0.24 to 1.53 & & 2.39 & 0.98 to 5.84 & \\
\hline Ever smoked & 1.08 & 0.82 to 1.42 & 0.57 & 1.04 & 0.76 to 1.44 & 0.80 \\
\hline Current smoker & 1.65 & 1.32 to 2.06 & $<0.001$ & 1.96 & 1.42 to 2.69 & $<0.001$ \\
\hline Pack-years of smoking (per 10 pack-years) & 1.10 & 1.05 to 1.15 & $<0.001$ & 1.15 & 1.07 to 1.23 & $<0.001$ \\
\hline Education (per category) & 0.93 & 0.87 to 1.00 & 0.052 & 0.96 & 0.87 to 1.06 & 0.45 \\
\hline Systolic blood pressure (quintiles) & & & 0.52 & & & 0.010 \\
\hline 1 & 1.00 & - & & 1.00 & - & \\
\hline 2 & 0.79 & 0.57 to 1.09 & & 1.71 & 1.08 to 2.71 & \\
\hline 3 & 0.93 & 0.69 to 1.26 & & 1.76 & 1.13 to 2.73 & \\
\hline 4 & 0.99 & 0.74 to 1.34 & & 1.88 & 1.21 to 2.92 & \\
\hline
\end{tabular}

*Unreported income in same category as lowest income for estimating effect per category, but also estimated as a separate effect.

tIn the dataset, male subjects who reported they were homemakers were given a missing value for current working status to help preserve anonymity. Since these participants could not be identified they were not included in the analysis.

BMI, body mass index; HR, hazard ratio.

function with metabolic syndrome $e^{36}$ and the increased mortality from COPD in those with metabolic syndrome. ${ }^{37}$

Another common feature of both cardiovascular disease and poor ventilatory function is low-grade systemic inflammation, ${ }^{38}$ and this has been used to explain at least part of the association between the two conditions. ${ }^{39} 40$ Low-grade inflammation is, however, also associated with poor intrauterine growth, as shown in both the MIDSPAN study ${ }^{41}$ and the North Finnish birth cohort, ${ }^{42-44}$ and this association may also reflect a common origin.

The observation that low FVC, type II diabetes, cardiovascular disease and low-grade systemic inflammation are all associated with each other and with low birth weight does not demonstrate that these conditions have a common cause, nor that low birth weight itself is the cause of the different conditions. Low birth weight is itself a combination of premature birth and poor fetal growth, and its causes are poorly understood. There is no guarantee that increasing birth weights within the normal range would reduce any of the associated conditions. Nor should it be assumed that, because the origins of the conditions are in early life, later efforts to mitigate the consequences would be ineffective. Nevertheless, the observation provides a potentially fruitful hypothesis to explain a very common condition.

Table 3 Association of spirometric values with mortality

\begin{tabular}{|c|c|c|c|c|c|c|c|c|c|}
\hline & \multicolumn{3}{|c|}{ Unadjusted $^{*}$} & \multicolumn{3}{|c|}{ Adjusted $\dagger$} & \multicolumn{3}{|c|}{ Mutually adjusted $\ddagger$} \\
\hline & HR & $95 \% \mathrm{Cl}$ & $\mathrm{p}$ Value & HR & $95 \% \mathrm{Cl}$ & $\mathrm{p}$ Value & HR & $95 \% \mathrm{Cl}$ & p Value \\
\hline \multicolumn{10}{|l|}{ Men } \\
\hline $\mathrm{FEV}_{1}$ & 0.82 & 0.79 to 0.86 & $<0.001$ & 0.92 & 0.88 to 0.97 & 0.001 & 0.98 & 0.90 to 1.07 & 0.72 \\
\hline FVC & 0.78 & 0.74 to 0.83 & $<0.001$ & 0.89 & 0.83 to 0.94 & $<0.001$ & 0.90 & 0.81 to 1.00 & 0.049 \\
\hline $\mathrm{FEV}_{1} / \mathrm{FVC}$ & 0.91 & 0.84 to 0.99 & 0.024 & 0.99 & 0.91 to 1.08 & 0.77 & & & \\
\hline \multicolumn{10}{|l|}{ Women } \\
\hline $\mathrm{FEV}_{1} / \mathrm{FVC}$ & 0.90 & 0.79 to 1.02 & 0.11 & 0.99 & 0.87 to 1.14 & 0.93 & & & \\
\hline
\end{tabular}


The ARIC study is a large prospective study of good quality. Although the conclusions of a multiple regression analysis may be influenced by the relative quality of the information on different variables so that the better measured variables will tend to dominate the analyses, this does not seem to be a likely problem in this instance. If the results in table 3 were simply an artefact related to data quality, it would be expected that the more easily measured variable (in this case $\mathrm{FEV}_{1}$ ) would dominate the analysis. In the end it is the FVC that dominates the regression. There is no reason to suppose that the results from this large American study would be different in another population.

The results reported here apply to asymptomatic people. We looked at this group because we were interested in the association between mortality and spirometric values in the general population independent of overt obstructive disease. This group nevertheless has a substantial number of people with airway obstruction. Our results should not, however, be extrapolated to symptomatic populations. When we re-ran the analyses on this group, the results were different (see table E1 in the online supplement). Here all three spirometric measures $\left(\mathrm{FEV}_{1}, \mathrm{FVC}\right.$ and the $\mathrm{FEV}_{1} / \mathrm{FVC}$ ratio) were associated with mortality and, when $\mathrm{FEV}_{1}$ and $\mathrm{FVC}$ were mutually adjusted for, each provided an estimated HR of 0.92 for both men and women. Only the HR for $\mathrm{FEV}_{1}$ in men was significantly different from 1 , which may partly reflect the relatively small sample size of this group.

These findings may provide a partial explanation for why investigators have found that $\mathrm{FEV}_{1}$ rather than a measure of air flow obstruction predicts the prognosis of airway obstruction. ${ }^{45-47}$ The more obvious staging by the extent of the reduction in $\mathrm{FEV}_{1} / \mathrm{FVC}$ ratio would clearly not be as effective at estimating prognosis in this group at least. Although FVC might theoretically be more appropriate, the strong correlation with $\mathrm{FEV}_{1}$ makes the latter an adequate marker.

Survival in asymptomatic adults without chronic respiratory diagnoses or persistent respiratory symptoms is associated with FVC and not with airway obstruction as measured by the $\mathrm{FEV}_{1} /$ FVC ratio. The relation of $\mathrm{FEV}_{1}$ to survival is indeed strong, but secondary to the association of $\mathrm{FEV}_{1}$ to $\mathrm{FVC}$. The association with survival is not explained by age, anthropometry, smoking, income, occupation or blood pressure. As FVC later in life, cardiovascular risk, type II diabetes mellitus and low-grade systemic inflammation are all associated with poor fetal growth, these other conditions may be partly responsible for the poor survival in those with low FVC.

Acknowledgements We would like to express our gratitude to the investigators and staff of the ARIC study and to Professor Neil Pride and Dr Sean Coady for helpful comments on an earlier draft.

Funding The Atherosclerosis Risk in Communities Study (ARIC) is conducted and supported by the NHLBI in collaboration with the ARIC Study Investigators. This manuscript was prepared using a limited access dataset obtained from the NHLBI and does not necessarily reflect the opinions or views of the ARIC investigators or the NHLBI. RH was supported by the Department of Health Policy Research Programme.

Competing interests None

Ethics approval The ARIC study was approved by local institutional review boards in the USA and the analysis was approved by the Imperial College research ethics committee.

Contributors PB had the original idea and wrote the first draft of the introduction and discussion. $\mathrm{RH}$ undertook the analysis and wrote the first draft of the methods and results.

Provenance and peer review Not commissioned; externally peer reviewed.

\section{REFERENCES}

1. Beaty TH, Cohen BH, Newill CA, et al. Impaired pulmonary function as a risk factor for mortality. Am J Epidemiol 1982;116:102-13.
2. Peto R, Speizer FE, Cochrane AL, et al. The relevance in adults of air-flow obstruction, but not of mucus hypersecretion, to mortality from chronic lung disease. Am Rev Respir Dis 1983;128:491-500.

3. Friedman GD, Klatsky AL, Siegelaub AB. Lung function and outcome of myocardial infarction. N Engl J Med 1976;295:1323.

4. Lange $\mathbf{P}$, Nyboe J, Jensen $\mathrm{G}$, et al. Ventilatory function impairment and risk of cardiovascular death and of fatal or non-fatal myocardial infarction. Eur Respir $\mathrm{J}$ 1991;4:1080-7.

5. Sin D, Man SFP. Why are patients with chronic obstructive pulmonary disease at increased risk of cardiovascular diseases? the potential role of systemic inflammation in chronic obstructive pulmonary disease. Circulation 2003;107:1514-19.

6. Anderson HR, Vallance P, Bland JM, et al. Prospective study of mortality associated with chronic lung disease and smoking in Papua New Guinea. Int J Epidemiol 1988;17:56-61.

7. The ARIC Investigators. The Atherosclerosis Risk In Communities (ARIC) study: design and objectives. Am J Epidemiol 1989;129:687-702.

8. Ferris BG. Epidemiology standardization project (American Thoracic Society). Am Rev Respir Dis 1978;118:1-120.

9. Anon. ATS statement-Snowbird workshop on standardization of spirometry Am Rev Respir Dis 1979:119:831-8.

10. Olofson J, Skoogh BE, Bake B, et al. Mortality related to smoking habits, respiratory symptoms and lung function. Eur $J$ Respir Dis 1987;71:69.

11. Fried LP, Kronmal RA, Newman AB, et al. Risk factors for 5-year mortality in older adults: the cardiovascular health study. JAMA 1998;279:585-92.

12. Kannel WB, Hubert H, Lew EA. Vital capacity as a predictor of cardiovascular disease: the Framingham study. Am Heart J 1983;105:311.

13. Keys A, Aravanis $\mathrm{C}$, Blackburn $\mathrm{H}$, et al. Lung function as a risk factor for coronary heart disease. Am J Public Health 1972;62:1506.

14. Hyatt R, Cowl C, Bjoraker J, et al. Conditions associated with an abnormal nonspecific pattern of pulmonary function tests. Chest 2009;135:419.

15. Stănescu D. Small airways obstruction syndrome. Chest 1999;116:231.

16. Macklem PT. Therapeutic implications of the pathophysiology of COPD. Eur Respir J 2010;35:676

17. Kan H, Heiss G, Rose $\mathrm{K}$, et al. Traffic exposure and lung function in adults: the atherosclerosis risk in communities study. Thorax 2007;62:873.

18. Schroeder E, Welch V, Couper D, et al. Lung function and incident coronary heart disease: the atherosclerosis risk in communities study. Am J Epidemiol 2003; 158:1171

19. Yeh H, Punjabi N, Wang N, et al. Vital capacity as a predictor of incident type 2 diabetes: the atherosclerosis risk in communities study. Diabetes Care 2005:28:1472.

20. Kaminsky D. Spirometry and diabetes: implications of reduced lung function. Diabetes Care 2004;27:837.

21. Yeh H, Punjabi N, Wang N, et al. Cross-sectional and prospective study of lung function in adults with type 2 diabetes: the atherosclerosis risk in communities (ARIC) study. Diabetes Care 2008;31:741.

22. Barker DJP, Godfrey KM, Fall C, et al. Relation of birth weight and childhood respiratory infection to adult lung function and death from chronic obstructive airways disease. BMJ 1991;303:671-5.

23. Lopuhaa CE, Roseboom TJ, Osmond C, et al. Atopy, lung function and obstructive airways disease after prenatal exposure to famine. Thorax 2000;55:555-61.

24. Lima RdC, Victora C, Menezes AMB, et al. Respiratory function in adolescence in relation to low birth weight, preterm delivery, and intrauterine growth restriction. Chest 2005; 128:2400-7.

25. He 0-, Wong T-, Du L, et al. Birth weight and lung function in a cohort of Chinese school children. Pediatr Pulmonol 2009:44:662-8.

26. Rona RJ, Gulliford MC, Chinn S. Effects of prematurity and interuterine growth on respiratory health and lung function in childhood. BMJ 1993;306:817-20.

27. Orfei L, Strachan DP, Rudnicka AR, et al. Early influences on adult lung function in two national British cohorts. Arch Dis Child 2008;93:570-4.

28. Stein CE, Kumaran K, Fall CHD, et al. Relation of fetal growth to adult lung function in south India. Thorax 1997;52:895-9.

29. Edwards CA, Osman LM, Godden DJ, et al. Relationship between birth weight and adult lung function: controlling for maternal factors. Thorax 2003;58:1061-5.

30. Dezateux C, Lum S, Hoo A, et al. Low birth weight for gestation and airway function in infancy: exploring the fetal origins hypothesis. Thorax 2004;59:60-6.

31. Canoy D, Pekkanen J, Elliott $\mathrm{P}$, et al. Early growth and adult respiratory function in men and women followed from the fetal period to adulthood. Thorax 2007:62:396-402.

32. Hancox RJ, Poulton R, Greene JM, et al. Associations between birth weight, early childhood weight gain and adult lung function. Thorax 2009;64:228-32

33. Pei L, Chen G, Mi J, et al. Low birth weight and lung function in adulthood: retrospective cohort study in China, 1948-1996. Pediatrics 2010;125:e899-905.

34. Huxley $\mathbf{R}$, Owen $\mathbf{C}$, Whincup $\mathrm{P}$, et al. Is birth weight a risk factor for ischemic heart disease in later life? Am J Clin Nutr 2007:85:1244-50.

35. Whincup P, Kaye S, Owen C, et al. Birth weight and risk of type 2 diabetes: a systematic review. JAMA 2008;300:2886-97.

36. Nakajima K, Kubouchi Y, Muneyuki T, et al. A possible association between suspected restrictive pattern as assessed by ordinary pulmonary function test and the metabolic syndrome. Chest 2008:134:712-18.

37. Lee $\mathbf{H}$, Chung S, Lopez V, et al. Association of FVC and total mortality in US adults with metabolic syndrome and diabetes. Chest 2009;136:171-6. 
38. Gan W0, Man SFP, Senthilselvan A, et al. Association between chronic obstructive pulmonary disease and systemic inflammation: a systematic review and a meta-analysis. Thorax 2004;59:574-80.

39. Engström G, Lind P, Hedblad B, et al. Lung function and cardiovascular risk: relationship with inflammation-sensitive plasma proteins. Circulation 2002;106:2555-60.

40. Barnes PJ, Celli BR. Systemic manifestations and comorbidities of COPD. Eur Respir J 2009;33:1165.

41. Sattar N, McConnachie A, O'Reilly D, et al. Inverse association between birth weight and C-reactive protein concentrations in the MIDSPAN family study. Arterioscler Thromb Vasc Biol 2004;24:583-7.

42. Tzoulaki I, Jarvelin M, Hartikainen A, et al. Size at birth, weight gain over the life course, and low-grade inflammation in young adulthood: Northern Finland 1966 birth cohort study. Eur Heart J 2008;29:1049-56.

43. Canoy D, Pouta A, Ruokonen A, et al. Weight at birth and infancy in relation to adult leukocyte count: a population-based study of 5619 men and women followed from the fetal period to adulthood. J Clin Endocrinol Metab 2009;94:1916-22.

44. Pirkola J, Vääräsmäki M, Ala-Korpela M, et al. Low-grade, systemic inflammation in adolescents: association with early-life factors, gender, and lifestyle. Am J Epidemio 2010;171:72-82

45. Global Initiative for Chronic Obstructive Lung Disease (GOLD). Global Strategy for the Diagnosis, Management and Prevention of Chronic Obstructive Pulmonary Disease. Medical Communications Resources, 2008. http://www. goldcopd.org.

46. Celli B, Cote C, Marin J, et al. The body-mass index, airflow obstruction, dyspnea and exercise capacity index in chronic obstructive pulmonary disease. $N$ Engl $\mathrm{J}$ Med 2004;350:1005.

47. Puhan M, Garcia-Aymerich J, Frey M, et al. Expansion of the prognostic assessment of patients with chronic obstructive pulmonary disease: the updated BODE index and the ADO index. Lancet 2009:374:704-11.

\section{Pulmonary puzzle}

\section{An unusual case of refractory asthma}

\section{CLINICAL PRESENTATION}

A 34-year-old woman with atopic asthma since the age of 16 years presented with increasing exertional dyspnoea and wheeze over a period of 12 months. She had no symptomatic benefit from escalation of bronchodilator therapy and her peak expiratory flow (PEF) remained reduced despite multiple courses of oral corticosteroid. Lung function at rest showed mild air flow obstruction with forced expiratory volume in $1 \mathrm{~s}\left(\mathrm{FEV}_{1}\right)$ of 2.271 $(75 \%$ predicted), forced vital capacity (FVC) of $3.131(89 \%$ predicted) and a $\mathrm{FEV}_{1} / \mathrm{FVC}$ ratio of $73 \%$. Both inspiratory and expiratory limbs of the flow-volume loop (FVL) had a flattened appearance. She was also noted to have a right-sided aortic knuckle on chest x-ray.

To determine the mechanisms of exercise limitation, she underwent an incremental cardiopulmonary exercise test on a cycle ergometer with maximal FVL measured during exercise. Her exercise performance was limited by breathlessness, achieving a peak work rate of 77 Watts (55\% predicted) and a peak oxygen uptake of $1.171 / \mathrm{min}$ ( $61 \%$ predicted). Endexercise minute ventilation was $49.11 / \mathrm{min}(62 \%$ of predicted maximal voluntary ventilation), indicating a normal breathing reserve. However, the ventilatory pattern was abnormal with over-reliance on respiratory frequency ( 52 breaths/min at peak exercise) and restriction in tidal volume (0.83 1 at peak exercise). In addition, the maximal FVL changed during exercise (figure 1).

\section{QUESTION}

What is the diagnosis?

See page 74 for answer

\section{Wai-Ting Nicola Lee ${ }^{1}$, Aileen Brown ${ }^{2}$, Steve Banham Hamish Walker ${ }^{3}$, Martin Johnson ${ }^{1}$}

${ }^{1}$ Department of Respiratory Medicine, Gartnavel General Hospital, Glasgow, UK; ${ }^{2}$ Respiratory Laboratory, Gartnavel General Hospital, Glasgow, UK; ${ }^{3}$ Scottish Adult Congenital Cardiac Service, Golden Jubilee National Hospital, Glasgow, UK

Correspondence to Dr Wai-Ting Nicola Lee, Department of Respiratory Medicine, Gartnavel General Hospital, 1053 Great Western Road, Glasgow G12 OYN, UK; waiting.lee@nhs.net

\section{Competing interests None}

Patient consent Obtained.

Provenance and peer review Not commissioned; externally peer reviewed.

Published Online First 19 November 2010

Thorax 2011:66:54. doi:10.1136/thx.2010.139212
Figure 1 Maximal flow-volume loops performed during incremental cardiopulmonary exercise test showed that, during exercise, peak inspiratory flow (PIF) fell from $5.1 \mathrm{l} / \mathrm{s}$ at rest to $3.2 \mathrm{l} / \mathrm{s}$ and peak expiratory flow (PEF) from $3.36 \mathrm{l} / \mathrm{s}$ at rest to $2.35 \mathrm{l} / \mathrm{s}$. This inspiratory and expiratory flow limitation led to a $20 \%$ reduction in both forced expiratory volume in $1 \mathrm{~s}$ and inspiratory capacity during exercise. PIF and PEF returned to resting values at recovery.

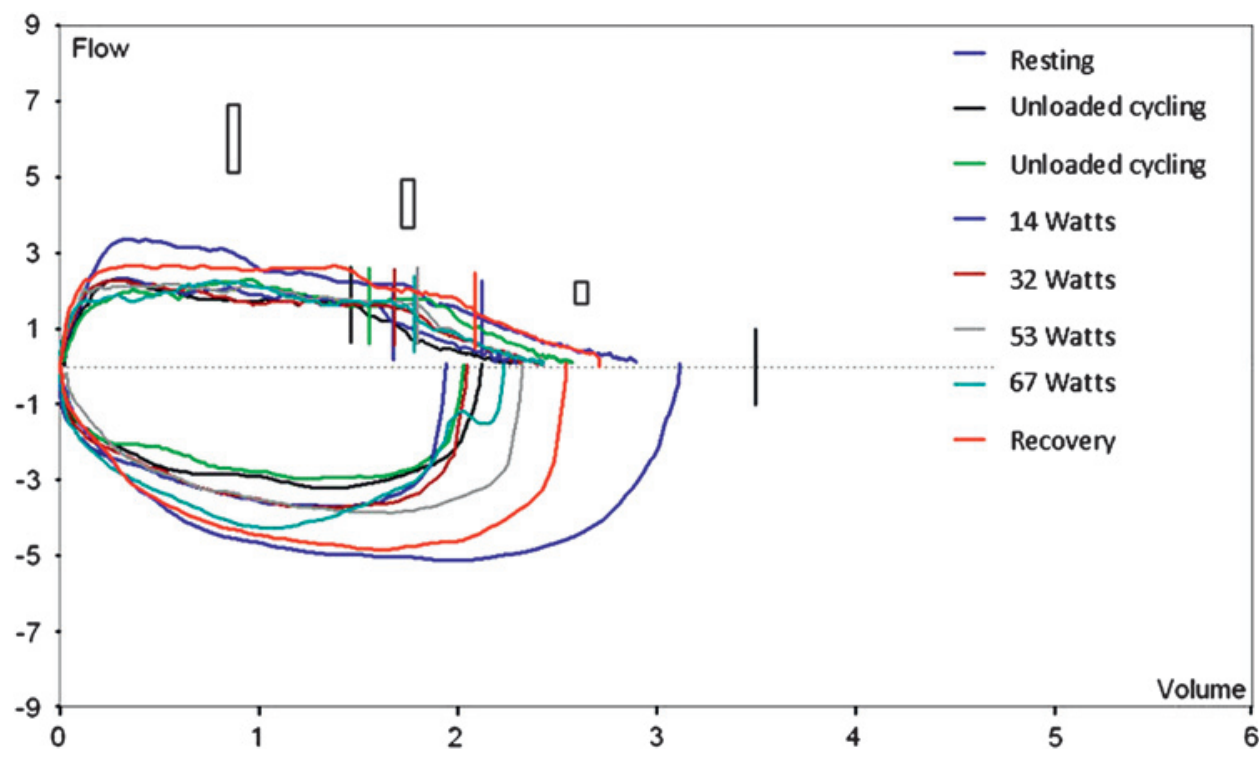

